\title{
KONSEP KEINDAHAN BUDAYA RUPA DALAM NASKAH SUNDA KUNO
}

Jamaludin

\begin{abstract}
Some ancient Sundanese texts that have been traced are Sewaka Darma (kropak 408) which contains the concept of visual beauty (appearance) in various contexts ie place or environment in the form of a garden by making the composition or composition of various types of plants both flowering and which is not. The diversity of ornamental plants is characterized among others by the shape of the leaves, the shape and color of flowers, and the height of each plant. The beauty in a metaphysical context is also found in relation to death. Death is a perfect beauty. The image of beauty of the palace and the state of heaven or of the gods is depicted in the form of a palace construction which uses precious metals of gold, silver, as well as metals such as iron which are processed into beauty.
\end{abstract}

Keywords: beauty, ancient Sundanese scripts, meaning

\section{PENDAHULUAN}

Penelitian tentang estetika atau konsep keindahan yang terdapat dalam naskah Sunda kuno bertujuan untuk mencari konsep dasar dan awal mengenai bentuk-bentuk keindahan dalam konteks budaya rupa (visual culture) yang ada dalam budaya Sunda. Keindahan visual yang diteliti terutama yang berhubungan dengan budaya hunian masyarakat Sunda jaman dulu. Pendekatan penelitian menggunakan metoda analisis deskripsi.

Sumber utama bahan penelitian adalah naskah-naskah Sunda kuno yang telah ditransliterasi dan diterjemahkan. Naskahnaskah tersebut aslinya terdapat di Bagian Naskah Museum Nasional dan Perpustakaan Nasional. Sumber atau tempat asal naskahnaskah tersebut antara lain Kabuyutan Ciburuy Garut dan Kabuyutan Kawali Ciamis. Penelitian terhadap naskah-naskah Sunda kuno telah dilakukan sejak masa kolonial oleh para ahli Belanda yang tergabung dalam Bataviasch Genootschap van Kunsten en Wetenschapen $(\mathrm{BGKW})$, organisasi ilmu pengetahuan dan seni yang didirikan pada 1778. Diantara peneliti itu adalah K.F. Holle, C.M Pleyte dan J. Noordyun. K.F. Holle adalah orang pertama yang mengumumkan keberadaan tiga naskah Sunda kuno dalam daun lontar yang masing-masing diberi kode MS (Manuschrif Soenda) A, B dan C. MSA kemudian diberi kode Kropak 632 berisi Amanat Galunggung, MSB Kropak 630, berjudul Sanghyang Siksakandang Karesian dan MSC Kropak 631 berjudul Candrakirana (Undang A Darsa, Edi S Ekadjati, 2006).

Pada masa kemerdekaan, penelitian terhadap naskah Sunda kuno dilakukan oleh para ahli filologi Indonesia, sebagian menggunakan hasil penelitian terdahulu. Peneliti tersebut adalah Drs Atja, Saleh Danasasmita, 
Prof. Dr. Ayatrohaedi, Prof. Dr Edi S. Ekadjati, Tien Wartini dan Undang Ahmad Darsa. Naskah-naskah tersebut disimpan dalam kotak yang diberi nomor sebagai katalog, yang disebut Kropak. Beberapa naskah tersebut memuat beberapa keterangan mengenai sejarah raja-raja, ajaran dan kosmologi, sedikit mengenai bangunan, pertukangan. Sebagian besar naskahnaskah tersebut ditulis dengan disertai waktu penulisan, sehingga memudahkan menelusuri kondisi saat itu dalam kerangka sejarah umum.

Penelitian yang telah dilakukan terhadap naskah Sunda kuno umumnya pemahaman terhadap isi keseluruhan yaitu gambaran umum yang terdapat dalam suatu kumpulan naskah Sunda kuno.

\section{DASAR TEORITIS}

\section{Naskah Sunda Kuno}

Menurut data yang ada beberapa naskah Sunda kuno yang telah ditransliterasi dan diterjemahkan adalah:

a. Sanghyang Siksakandang Karesian (Kropak 630).

Naskah ini memberikan gambaran tentang pedoman moral umum untuk kehidupan bermasyarakat pada masa itu, termasuk berbagai ilmu yang harus dikuasai sebagai bekal kehidupan praktis sehari-hari. Penuturannya berpijak pada kehidupan di dunia dalam konteks bernegara (Saleh Danasamita, dkk, 1987:5). Ada pendapat yang mengatakan bahwa naskah ini "semacam ensiklopedia". b. Sewaka Darma (Kropak 408)

Naskah ini merupakan salah satu bukti mengenai pernah berkembangnya aliran Tantrayana di Jawa Barat pada masa silam, meskipun terlihat adanya campuran dengan Budisme dan "agama pribumi" karena adanya unsur byang tetap dibedakan dengan dewata walaupun tempat tinggal dewata disebut kahiyangan. Naskah asli tersimpan di Perpustakaan Nasional Jakarta. (Salah Danasasmita, dkk, 1987)

c. Amanat Galunggung (Kropak 632)

Naskah ini berisikan ajaran hidup dalam bentuk nasihat yang disampaikan oleh seorang raja kepada anak cucu dan masyarakat luas.

d. Carita Parahyangan (sebagian dari Kropak 406) ${ }^{1}$

Naskahi ini berisikan cerita keadaan kerajaan pulau Jawa yang terfokus ke wilayah Jawa Barat dan sebagian Jawa Tengah/Timur termasuk menceritakan raja Sanjaya yang berangkat ke bagian timur.

e. Jatiraga (Kropak 422)

Naskah ini berisikan kosmologi Sunda kuno yang bersifat perpaduan dengan Budisme dan Hinduisme (Undang A. Darsa \& Edi S. Ekadjati, 2006)

f. Carita Ratu Pakuan (Kropak 410)

g. Kropak 420

Berisikan kosmologi dan ajaran moral religius Sunda kuno (Undang A. Darsa \& Edi S Ekadjati, 2006)

\footnotetext{
${ }^{1}$ Drs Atja, 1968, Tjarita Parabyangan, Naskab Titilar Karubun Urang Sunda Abad ka-16 Masebi, Yayasan Kebudayaan Nusalarang
} 
h. Kropak 421

Berisikan silsilah dan keturunan yang berkuasa atau minimal pernah memiliki pengaruh di wilayah Sunda yang berawal dari tokoh Siliwangi yang bergelar prabu dan berakhir dengan tokoh yang bergelar raden. Selain itu terdapat mantera Aji Cakra dan ajaran Islam.

\section{Konsep Keindahan dalam Naskah Sunda} Kuno

Dari hasil penelurusan sementara terhadap terjemahan naskah Sunda kuno yaitu Sewaka Darma (Kropak 408) dan Sanghyang Siksakandang Karesian (Kropak 630), terdapat beberapa konsep keindahan yang masing-masing memiliki makna atau konteks tertentu.

\section{Konteks Indah/Keindahan dalam Arti}

Taman

Salah satu naskah yang di dalamnya mengandung kata indah adalah Sewaka Darma (kropak 408) Naskah asli berada di Museum Nasional Jakarta. Dalam Sewaka Darma lembar 35, terdapat kata nyayu yang artinya diperindah. Konteks kalimat mengarah pada taman buatan. Lengkapnya:

Tuluy nyorang beunang nyayu

Tajur pinang

Kumara sinar hanjuang

Sasipat mata handeuleum

Salaput beubeung tatali kayu waduri

Manyara deung kembang bulan

Wera tumpang wera la(n)car
Kembang soka

Kupuracata

Kembang tere rane

Jahe si(n)gugu hanoja

Dilem padma putih

Manda kaki kembang susun

Kembang menur kembang bunga pala

Dara puspa kembang puspa gading

Malati kembang buru kajut

Kembang dongdo(ng)man

Kembang teleng bunga bireng

Kasumba deung kapuracata

Deung kembang jama(ng) katilu

Ki saruni keling kembang cina janaraya

Lalu menempuh tempat yang diperindah (taman)

Pohon pinang

Kemilau sinar hanjuang

Handeuleum segaris mata

Waduri setinggi leher

Lantana dan kembang bulan

Wera tumpang wera lancar

Bunga soka

Dan kapuracata

Bunga tere rane

Jahe singugu dan hanoja

Dilem dan teratai putih

Manda kaki dan kembang susun

Bunga menur dan bunga pala

Dara puspa dan puspa gading

Melati dan bunga huru kajut

Bunga dongdoman

Bunga telang dan bunga hitam

Kasumba dan kapuracata 
Dan bunga jamang katilu

Seruni keling kembang cina dan janaraya

Penerjemah memberi tambahan kata "taman" dalam tanda kurung, berdasarkan kalimat selanjutnya yang menceritakan tempat yang ditumbuhi berbagai macam tanaman. Arti luasnya adalah bahwa masyarakat jaman itu telah mengenal prinsip keindahan yang antara lain dengan cara menata atau membuat suatu lingkungan diatur sedemikian rupa sehingga menjadi indah. Tampak pula bahwa keindahan taman dibentuk dari keberagaman jenis tanaman yang masing-masing memiliki kekhasan sendiri dalam bentuk daun dan bunganya serta tinggi setiap tanaman seperti digambarkan dengan segaris mata dan setinggi leher. Perbedaan ketinggian atau ukuran vertikal juga menjadi bagian dari komposisi keindahan. Tampaknya taman tersebut dilengkapi kolam hias karena terdapat jenis bunga teratai putih. Teratai umumnya tumbuh di atas kolam.

Kata "nyayu” tampaknya dari kata "ayu” yang masih dipakai hingga sekarang tetapi mengalami perubahan arti yang sekarang sebutan lain untuk perempuan cantik.

\section{Keindahan Sebagai Makna Metafisik}

Kata indah atau keindahan yang bermakna metafisik antara lain terdapat naskah Sewaka Darma lembar 56 akhir dan lembar 57, yaitu:

Pwa Nilasita

Eta newek maneh

Ngabelaan sasra gewa(ng)
Sang Mardiyyanaba

Bali(k) dipana(h) ku Lasamana

Dinya kasorgaanana

Pwa Nilasita

Ia menikam diri sendiri

Membela keindahan yang gemilang

Sang Mardiyyanaba

Waktu pulang dipanah oleh Lasamana

Dalam kebahagiaanya

Penerjemah menjelaskan bahwa kata keindahan dalam kalimat di atas memiliki konteks atau perlambang kematian yang sempurna. Dengan kata lain, keindahan ini bersifat metafisik. Kematian adalah proses hidup yang sempurna yang dijalani dengan bahagia.

3. Keindahan dalam Konteks Rumah Tinggal Sementara gambaran tentang rumah, terdapat dalam naskah Sewaka Darma lempir 63, meskipun tampaknya rumah ini bukan rumah biasa tetapi rumah wiku atau semacam pendeta. Lengkapnya:

\section{Mangening na imah sarba kanycana}

Hurub hibar kadi bentang timur

Betan bulan eukeur purnama

Betan poyan sabingilan

Murub mu(n)car paka gonan

Kumenyar tan kapademan

Palu(ng)guban wiku tubu garya asi(b)

Lakesana ajar-ajaran

Sir saya ami-amilang

Geu(s) tuginya manah datang 
Kabeb dinya saur nu (ma)wa maha wisesa

Merenung di rumah serba kencana

Bersinar semarak seperti bintang timur

Seperti bulan sedang purnama

Seperti hari cerah sehabis hujan (?)

Terang kemilau seluruh tempat

Gemilang tak terpadamkan

Tempat tinggal wiku sejati yang penuh kasih

Berhasil melaksanakan ajaran

Hasrat damai (tenang) menghitunghitung

Sesampai di situ tibalah hati

Semua dalam ucapan yang membawa kemampuan.

Rumah yang indah dalam naskah di atas diuraikan dalam berbagai cara yang rinci yang menyangkut warna keemasan (serba kencana). Kata ini dapat diterjemahkan langsung yaitu rumah dengan warna keemasan atau karena mendapat cahaya matahari senja. seperti bintang timur dan seperti bulan sedang purnama menunjukkan pencahayaan rumah yang baik dalam arti terang. Adapun makna hari cerah sehabis hujan tampaknya menunjukkan kesegaran alam sekitar.

\section{Gambaran Istana Dewa (Kahiyangan)}

Salah satu naskah yang memuat gambaran istana/singgasana dewa (kahiyangan) adalah Sewaka Darma (Kropak 403) yang diduga berasal dari Priangan, menggunakan huruf Sunda, kemungkinan ditulis pada awal abad 18 Masehi. Naskah ini telah ditransliterasi oleh
Saleh Danasasmita, Ayatrohaedi, Tien Wartini dan Undang Ahmad Darsa (Danasasmita, dkk, 1987). Pada lempir (halaman) ke 51, 52 dan 53 terdapat gambaran singgasana Batara Isora, Batara Wisnu, Batara Mahadewa dan Batara Siwa.. Lengkapnya:

Ti timur batara isora

Kabyangan pirak putih

Tihangan pirak diukir

Bahan(n)a (pirak) sagala

Dihateupan pirak cina

Dituruban ku pirak dililinggaan pirak malaka

Didinding ku pirak keling

Imah manik dikaranca(ng)

Warnana ukir-ukiran

Direka ditiru kembang

Kahanan Hyang Isora

Husireun nu ngawerati

Dinya kasorgaanana

Dari timur Batara Isora

Kahiyangan perak putih

Tiangnya perak berukir

Bahannya serba perak

Beratapkan perak cina

Berbubungan perak berlilinggakan permata

Berlantai perak malaka

Berdinding perak keling

Rumah bertabur permata

Bermacam-macam ukiran 
Ukiran meniru bunga

Tempat tinggal Hyang Isora

Tujuan mereka yang tulus tapa

Dalam kebahagiannya.

5. Warna Sebagai Simbol Dewa dan Arah Mata Angin

Warna adalah salah satu elemen estetika atau keindahan dalam budaya rupa. Dalam naskah Sanghyang Siksakandang Karesian terdapat bagian yang menjelaskan keberadaan empat arah mata angin yang masing-masing merupakan kediaman sanghyang yang keempatnya diberi simbol dengan warna. Lengkapnya:

Lamun pabi kaopeksa sanghyang wuku lima (dina) bwana, boa balimpu ikang desa kabeh. Desa kabeh ngaranya: ppurba, daksina, pasima, utara, madya. Pruba, timur, kahanan Hyang Isora, putih rupanya: daksina, kidul, (kahanan Hyang Brahma, mirah rupanya; Pasima, kulon, kahanan Hyang Mahadewa, kuning (rupanya); utara, lor, kahanan Hyang Wisnu, jideung rupanya; mdya, tengah, kahanan Hyang Siwah, (aneka) warna rupanya. Nya mana sakitu sanghyang wuku lima dina bwana.

Kalau terpahami semua sanghiyang wuku lima di bumi tentu (tampak) menyenangkan (keadaan) semua tempat. Tempat itu disebut: purwa, daksina, pasima, utara, madya. Purba yaitu timur, tempat Hyang Isora, putih warnanya. Daksina yaitu selatan, tempat Hyang
Brahma, merah warnanya. Pasima yaitu barat, tempat Hiyang Mahadewa, kuning warnanya. Utara yaitu utara, tempat Hyang Wisnu, hitam warnanya. Madya yaitu tengah, tempat Hiyang Siwa, aneka macam warnanya. Ya sekian wuku lima di bumi

Bagian naskah tersebut menceritakan arah mata angin yang menjadi singgasana (kahiyangan) masing-masing dewa:

1. Timur, Batara Isora, warna putih, material perak

2. Selatan, Batara Brahma, warna merah, material tembaga/suasa

3. Tengah, Batara Siwa, warna terang, material aneka macam

4. Barat, Batara Mahadewa, warna kuning, material emas

5. Utara, Batara Wisnu, warna hitam, material besi

\section{Profesi Kesenirupaan dan Hasil Kreasi (Desain)}

Sebagai sebuah naskah yang dianggap "semacam ensiklopedia", naskah Sanghyang Siksakandang Karesian (Saleh Danasasmita, dkk, 1987) antara lain memuat berbagai jenis benda atau karya dari suatu profesi atau pertukangan yang ada pada masa itu. Pembuatan suatu karya, baik benda pakai selain berhubungan dengan aspek fungsi juga berhubungan dengan aspek keindahan benda tersebut, baik keindahan karena kemampuannya memenuhi fungsinya, seperti konsep estetika desain modern, maupun 
keindahan yang bersifat dekorasi atau hiasan serta makna simbolik di dalamnya.

\section{HASIL KAJIAN DAN PEMBAHASAN}

1. Permainan dan Tukang Membuat Mainan (Empul)

Hayang nyaho di pamaceuh ma: ceta maceuh, ceta nirus, tatapukan, babarongan, babakutrakan, ubang-ubangan, neureuy panca, munikeun le(m)bur), ngadu lesung, asup kana lantar, ngadu nini, sing sawatek. (ka)ulinan, hempul tanya. (lempir XVI)

Bila ingin tahu permainan seperti: ceta maceuh, ceta nirus, tatapukan, babarongan, babakutrakan, ubangubangan, neureuy panca, munikeun le(m)bur, ngadu lesung, asup kana lantar, ngadu nini, segala macam permainan, tanyalah empul.

\section{Karya Lukis, Pelukis}

Sa(r)wa lwira ning tulis ma: pupunjengan, hibinggulan, kekembangan, alas-alasan, urangurangan, memetahan, sisirangan, taruk hata, kembang tarate, sing sawatek tulis ma, tanya lukis. (XVI)

Segala macam lukisan, seperti: pupunjengan, hihinggulan, kekembangan, alas-alasan, urangurangan, memetahan, sisirangan, taruk hata, kembang teratai, segala macam lukisan, tanyalah pelukis.
3. Seni Ukir dan Ahli Ukiran (Maranggi)

Sa(r)wa lwira ning ukir ma: dinanagakeun, dibarongkeun, ditiru paksi, ditiru were, ditiru singha, sing sawatek ukir-ukir ma, marangguy tanya.(XVII)

Segala macam ukiran ialah; naga-nagaan, barong-barongan, ukiran burung, ukiran kera, ukiran singa, segala macam ukiran, tanyalah maranggi (ahli ukir).

4. Hasil Tempa/Perkakas/Senjata dan Pandai Besi

Sa(r)wa lwira ning teuteupaan ma telu ganggaman, palain. Ganggaman di sang prabu ma: pedang, abet, pamuk, golok, peso teundeut, kersi. Raksasa pinabka dewanya, ja paranti maehan sagala. Ganggaman sang wong tani ma: kujang, baliung, patik, kored, sadap. Detya pinabka dewanya, ja paranti ngala kikicapeun ïnumeun. Ganggaman sang pandita ma: kala katri, peso raut, peso dongdang, pangot, pakisi. Danawa pinabka dewanya, ja itu paranti kumeureut sagala. Nya mana teluna ganggaman palain deui di sang prebu, di sang wong tani, di sang pandita. Kitu lamun urang bayang nyabo di sarean(ana), eta mah panday tanya. (XVII)

Segala macam hasil tempaan, ada tiga macam yang berbeda. Senjata sang prabu ialah pedang, abet (pecut), pamuk, golok, peso teundeut, keris. Raksasa yang dijadikan dewanya, karena digunakan untuk membunuh. Senjata orang tani 
ialah kujang, baliung, patik, kored, pisau sadap. Detya yang dijadikan dewanya karena digunakan untuk mengambil apa yang dapat dikecap dan diminum. Senjata sang pendeta ialah kala patri, peso raut, peso dongdang, pangot, pakisi. Danawa yang dijadikan dewanya karena digunakan untuk mengerat segala sesuatu. Itulah ketiga jenis senjata yang berbeda pada sang rpebu, pada petani, pada pendeta. Demikianlah bila kita ingin tahu semuanya, tanyalah pandai besi.

\section{Seni Tekstil (batik) dan Ahli Tekstil}

Sa(r)wa lwira ning boeh ma: kembang $m u(n)$ cang, gagang senggang, sameleg, seumat kaburun, anyam cayut, sigeji, pasi-pasi, kalangkang ayakan, poleng re(ng)ganis, jaya(n)ti, cecempaan, paparanakan, mangin haris sili ganti, boeb siang, beberanatan, papakanan, surat awi, parigi nyengsoh, gaganjar, lusian besar, kampung jaya(n)ti, bujan riris, boeb alus, ragen panganten, sing sawatek boboeban ma pangeuyeuk tanya.(XVII, XVII)

Segala macam kain, seperti kembang muncang, gagang senggang, sameleg, seumat sahurun, anyam cayut, sigeji, pasi, kalangkang ayakan, poleng rengganis, jayanti, cecempaan, paparanakan, mangin haris, sili ganti, boeh siang, bebernatan, papakanan, surat awi, parigi nyengsoh, gaganjar, lusian besar, kampuh jayanti, hujan riris, boeh alus, ragen panganten, segala macam kain, tanyalah pangeuyeuk (ahli tekstil)

6. Mengatur Tempat dan Mangkubumi

Hayang nyaho dipatitis bumi ma: ngampibkeun bumi, masinikeun $n$ urang sajagat, parin pasini, ngadengdeng, maraspade, ngukur, nyaruakeun, nyipat, midana, lamun lubur dipidatar, ancol dipakpak, sing sawatek ampih-ampih ma mangkubumi tanya. (XIX)

Bila ingin tahu tentang cara-cara mengukur tanah seperti mengatur tempat, membagi-bagikan kepada seluruh rakyat, memberi tanda batas, meratakan, membersihkan lahan, mengukur, menyamakan, meluruskan, mengatur, bila tinggi didatarkan, bila rendah diratakan, segala macam pengaturan tempat, tanyalah mangkubumi

\section{KESIMPULAN}

Dari uraian di atas tampak bahwa kata keindahan ada dalam naskah Sunda kuno dalam berbagai bentuk dan makna. Kata nyanyu dalam naskah Sewaka Dharma menunjuk makna memperindah suatu lahan atau tempat menjadi suatu taman. Konsep keindahan telah ada dan dikenal dalam masyarakat Sunda dahulu dengan berbagai konteks atau bidang. Keindahan dalam bentuk visual atau fisik antara lain dalam bentuk merancang taman yang indah dengan berbagai 
ragam tanaman. Keindahan juga dipakai dalam bentuk metafisika atau simbolik.

Naskah Sanghyang Sikskandang

Karesian memuat konsep warna yang dipakai sebagai simbol arah mata angin yang juga merupakan tempat dewa tertentu. Temuan dalam naskah Sanghyang Sikskandang Karesian menunjukkan adanya berbagai profesi pertukangan dan karyanya dalam bidang seni terapan (desain). Adanya nama-nama khusus bagi profesi pertukangan dan karyanya itu menunjukkan bahwa budaya material atau budaya rupa telah ada, beragam dan berkembang.

\section{DAFTAR PUSTAKA}

Danasasmita, Saleh; Ayatrohaedi, Tien Wartini, Undang Ahmad Darsa

1987. Sewaka Darma (Kropak 403), Sanghyang Siksakandang Karesian (630), Amanat Galunggung (Kropak 632), Transkripsi dan Terjemahan, Departemen Pendidikan dan Kebudayaan

Darsa, Undang A, Edi S. Ekadjati

2006. Gambaran Kosmologi Sunda, Kiblat Buku Utama, Bandung

Danasasmita, Saleh, 2003. Nyukcruk Sajarah Pakuan Pajajaran jeung Prabu Siliwangi, Kiblat Buku Utama, Bandung

Danasasmita, Saleh,

2006. Mencari Gerbang Pakuan dan Kajian Lainnya Mengenai Budaya Sunda, Seri Sundalana 5, Pusat Studi Sunda, Bandung 